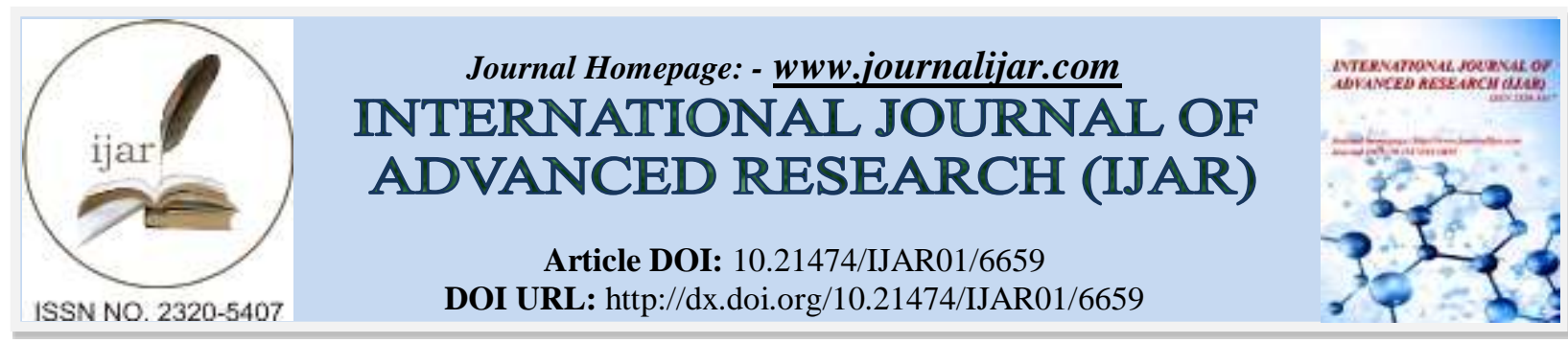

RESEARCH ARTICLE

\title{
GINGIVAL CHARACTERIZATION WITH PHOTOPOLYMERIZABLE RESIN IN TOTAL PROSTHESES: CLINICAL CASE REPORT.
}

\section{Danilo de Sousa Machado ${ }^{1}$, Maysa Gasques Teixeira ${ }^{1}$, Idiberto José Zotarelli Filho ${ }^{2}$, Leandro Moreira Tempest $^{1,2}$ and Vanda Rieko Fujita Miyazaki ${ }^{1,2}$.}

1. University Center North Paulista (Unorp) - São José do Rio Preto - SP, Brazil.

2. Post graduate and continuing education (Unipos), Street Ipiranga, 3460, São José do Rio Preto SP, Brazil 15020-040.

\section{Manuscript Info}

(.........................

Manuscript History

Received: 04 January 2018

Final Accepted: 06 February 2018

Published: March 2018

Keywords:-

Resin. Photopolymerizable resin. Total prostheses.

\section{Abstract}

Despite the advances in dentistry in relation to prevention, there are still many total edentulous patients who seek functional and aesthetic treatments. The present work presents an alternative technique for total dentures with the use of a new system facilitating the gingival characterization, causing it to become more natural, thus passing unnoticed, elevating the patient's self-esteem and well-being. The differential of this new method is the characterization with photopolymerizable resin of the SR NEXCO PASTE (light-cured composite) system, which has several color ranges, facilitating the mimicking of the gingival tissue. The prostheses performed followed the principles of aesthetics, resulting in a very satisfactory result, this material associated to the knowledge of facial aesthetics and smile physiology, makes it possible to obtain favorable conditions for patient satisfaction.

Copy Right, IJAR, 2018,. All rights reserved.

\section{Introduction:-}

The oral appearance is intimately related to facial harmony, thus being a prosthesis to be aesthetic due to the typical facial features, lip shape and support, smile harmony and profile $[1,2]$.

The amount gingival exposure is related to the attractiveness of the smile as well as the positioning of the dental elements. The various existing colors of oral mucosa challenge the technician to reproduce more naturally this gingival exposure $[3,4]$.

The use of composite resin can be found in the composite of Nexco Paste (Ivoclar Vivadent) and the Pala-Creative (Heraeus Kulzer) system able to reproduce an artificial gingiva similar to the natural one [5-8].

The present acrylic resin system (STG-VIPI) limits us to a small scale of colors, and the resins composed of having a wider range of colors allow us to better mimic the gingival tissue by means of stratification (gingival characterization) [9-11].

The objective of this study was to present a clinical case report on the use of photopolymerizable resins in total dentures for gingival characterization. 


\section{Case report:-}

A male patient, G.V.O, 64 years old, sought the Dentistry clinic of the University Center of North Paulista, desiring a pair of total dentures. After the diagnosis, it was proposed to make two complete dentures using gingival characterization using the Nexco system (Ivoclar Vivadent). The total prostheses were made according to the principles of reverse planning, and until the zygmatics were performed with characterization with the purpose of reproducing the colors of the buccal mucosa, avoiding a possible color discrepancy between them. After the approval of the patient, the Nexco Paste composite prosthesis for gingiva was completed, following the same characterization as in the urethoscope.

\section{Methods:-}

The clinical-laboratory sequence of making the total prosthesis is the same in the conventional manner. The differences in PT confection occur after the test of the teeth in wax, in the acrylization of the prosthesis. The steps are described below:

First step: After testing the wax teeth (Figs 2 and 3), remove all of the vestibular sculpture from the prosthesis, and then proceed to the partial acrylization of the prosthesis base with the conventional acrylization system.

Second step: after partial acrylization, the finishing and preparation of the surface of the acrylic resin is done for the application of SR Nexco Paste composite (Fig. 4).

Third step: sandblasting the surface to be characterized (vestibular) with aluminum oxide particles $(80-100 \mu \mathrm{m})$ and with 2 bar (29 psi) pressure. Remove residues with an air jet, taking care to keep the surface free of oil.

Step Four: Then apply the SR Connect brush on a thin layer and let it react for 2-3 minutes, then polymerize on the Lumamat 100 (light oven).

Step 5: After this, the SR Nexco stratification material is applied for stratification of the gingival (Figs 5 and 6). The colors used at this moment should follow the registration of color performed by the dentist surgeon, or by the characterized ceroplasty (Fig. 7).

Step Six: Polishing. Surface polishing in the usual way, with rubber polishers and silicone polishing wheels and universal polishing paste.

Figure 1:- Visualization of shades of the SR Nexco system (Ivoclar Vivadent)

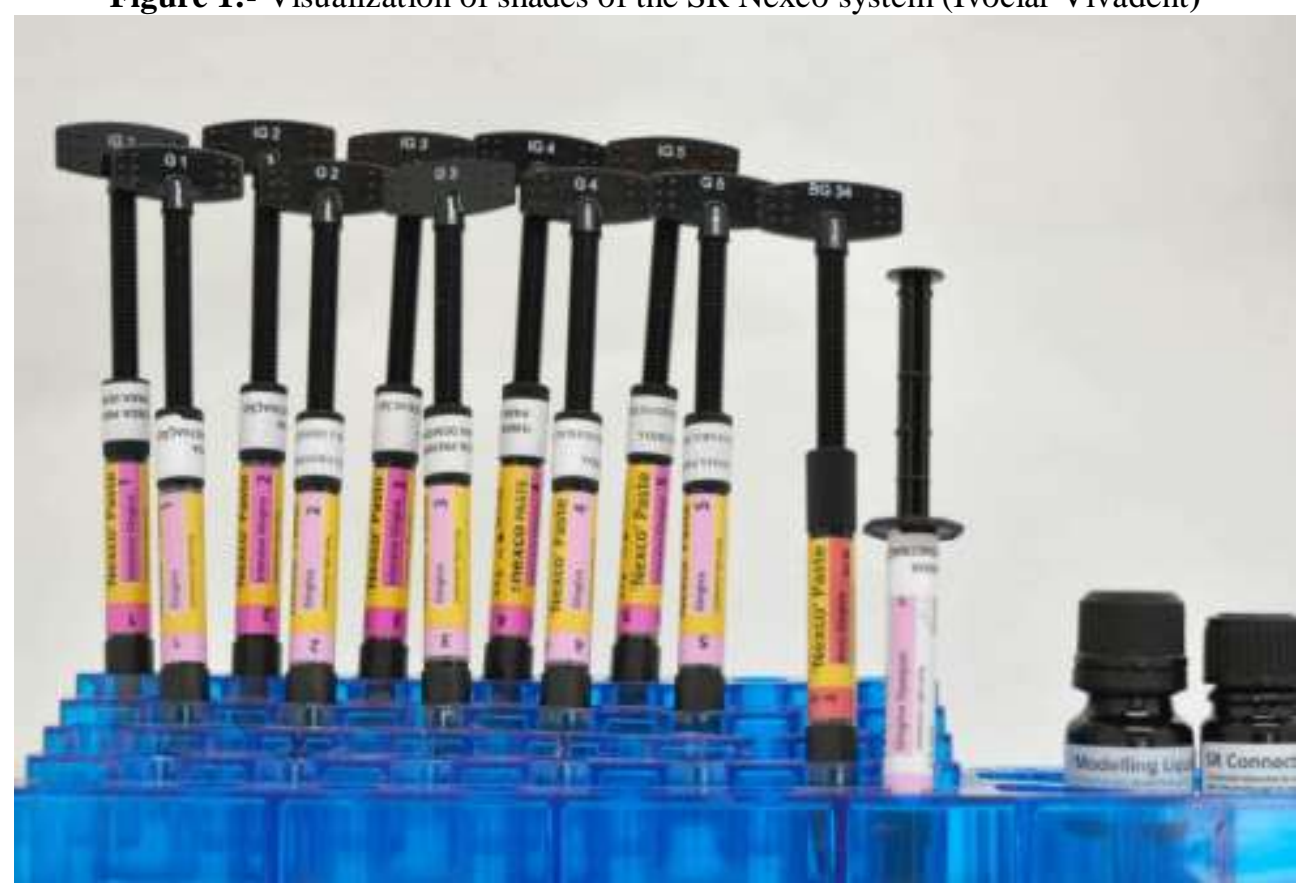


Figure 2:- Total dentures with gingival wax characterized, ready for teeth testing, and color analysis and gingival feature.

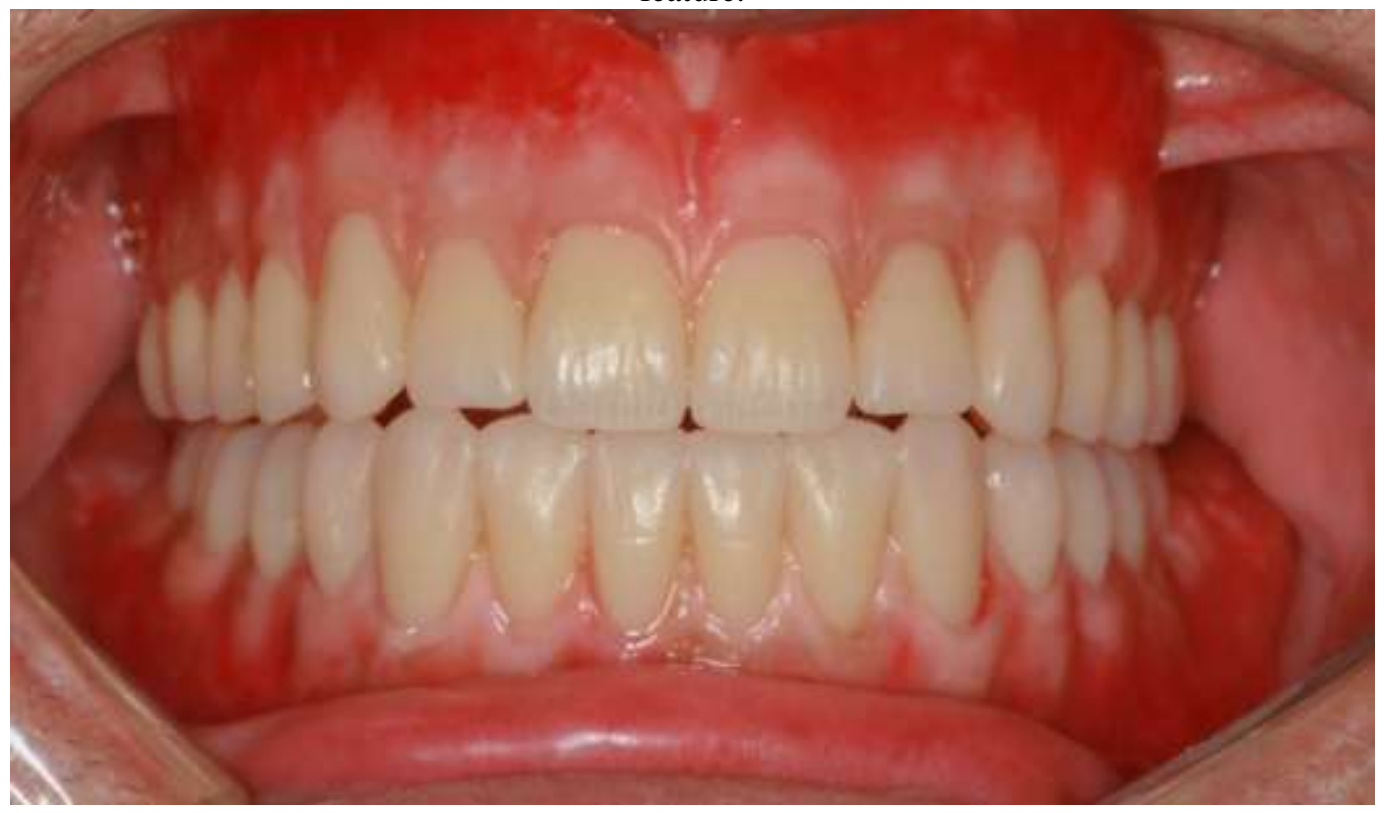

Figure 3:- Proof of the teeth of the total superior prosthesis. Notice the naturality achieved by the waxing of the

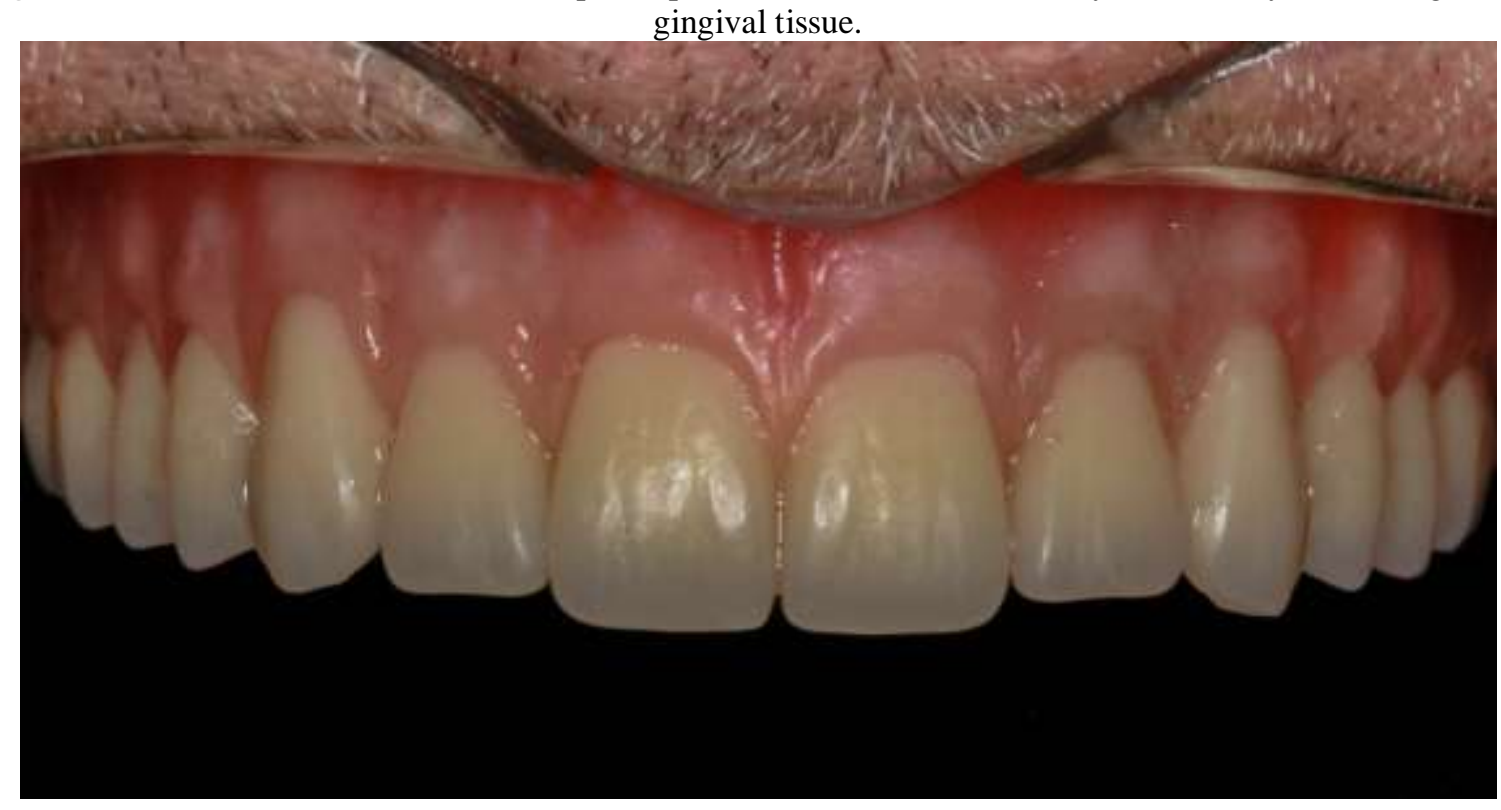


Figure 4:- Application of the first layer of the SR Nexco system, based on the acrylic resin.

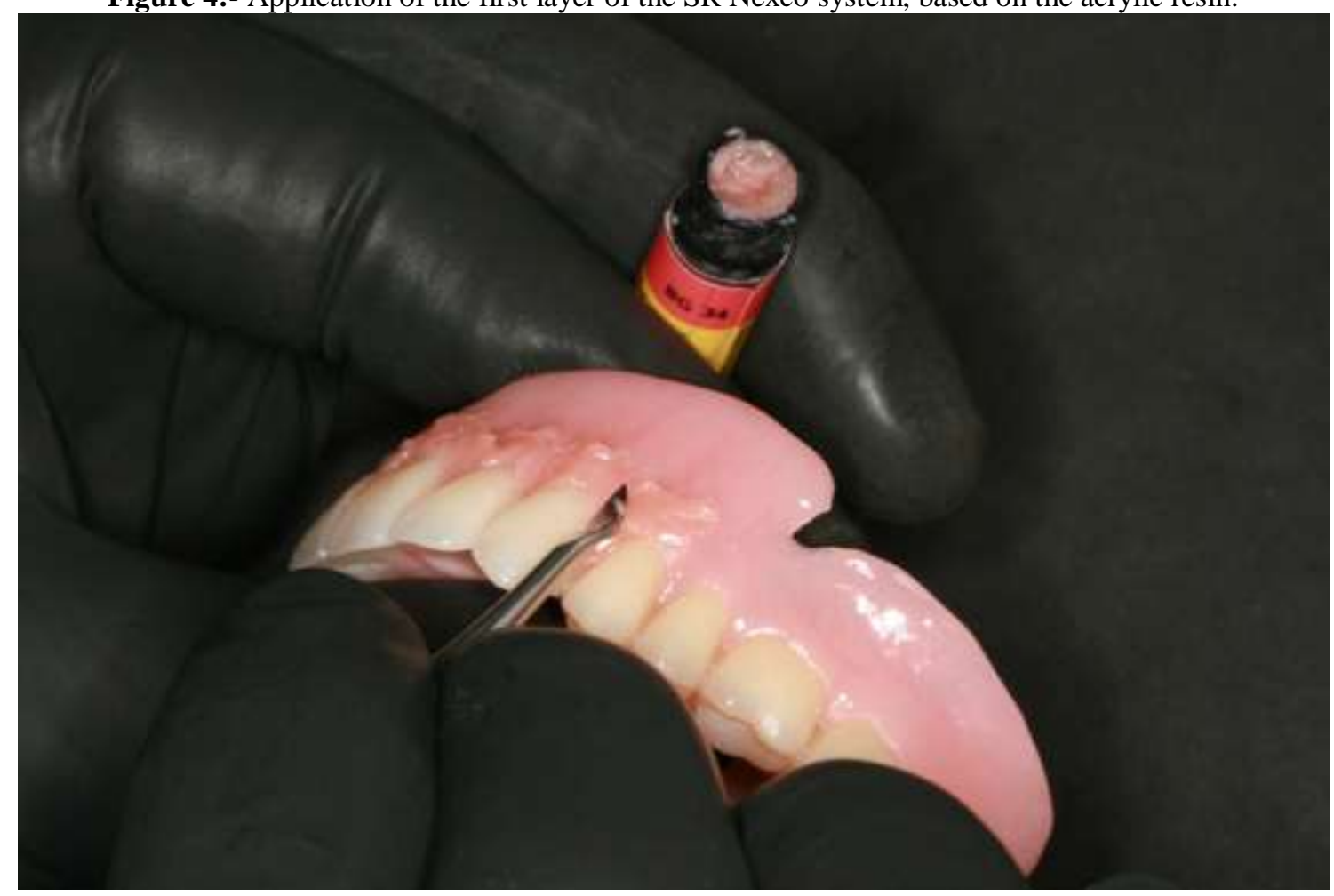

Figure 5:- Definition of contours and beginning of gingival sculpture.

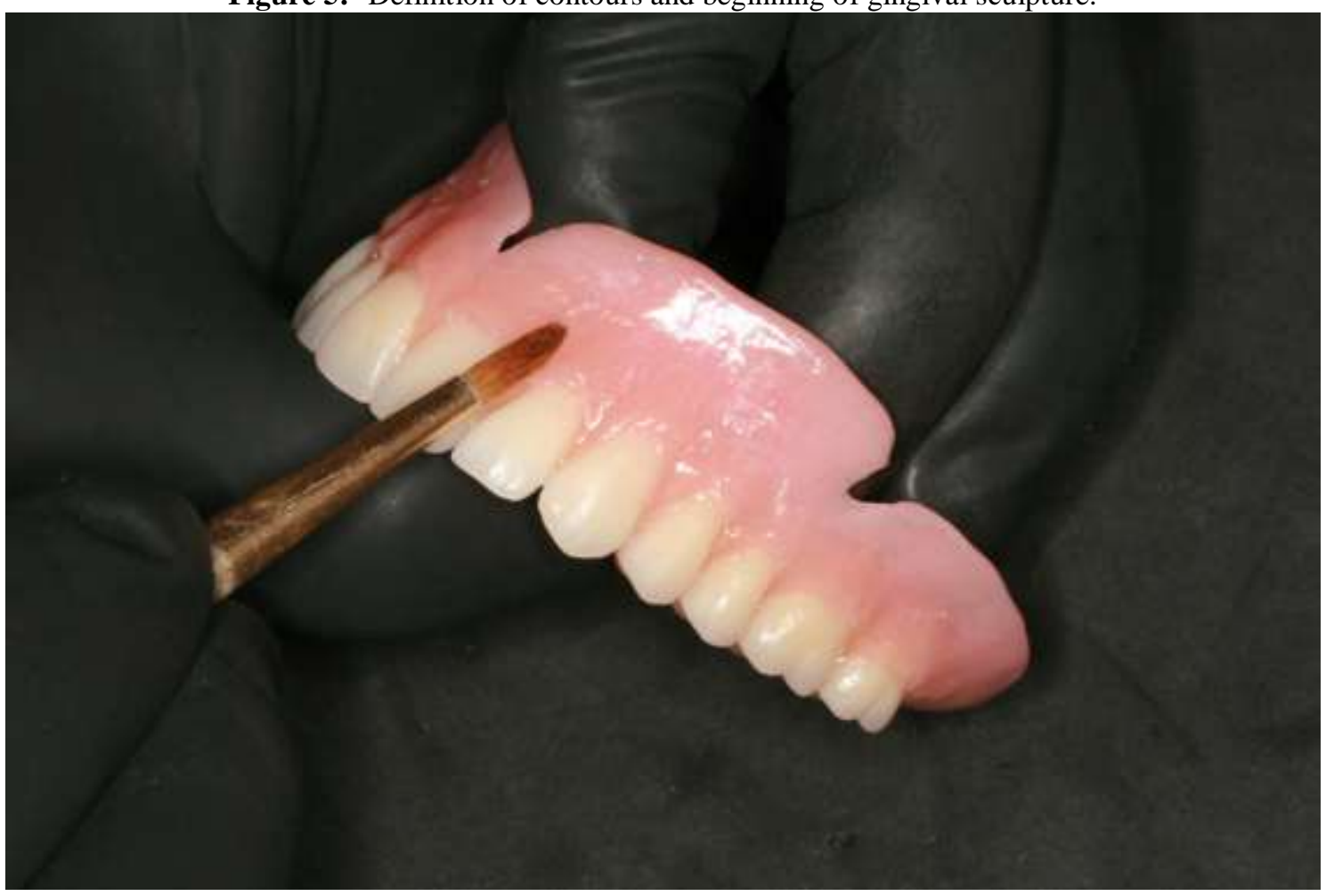


Figure 6:- Gingival characterization with the SR Nexco Paste 4 system.

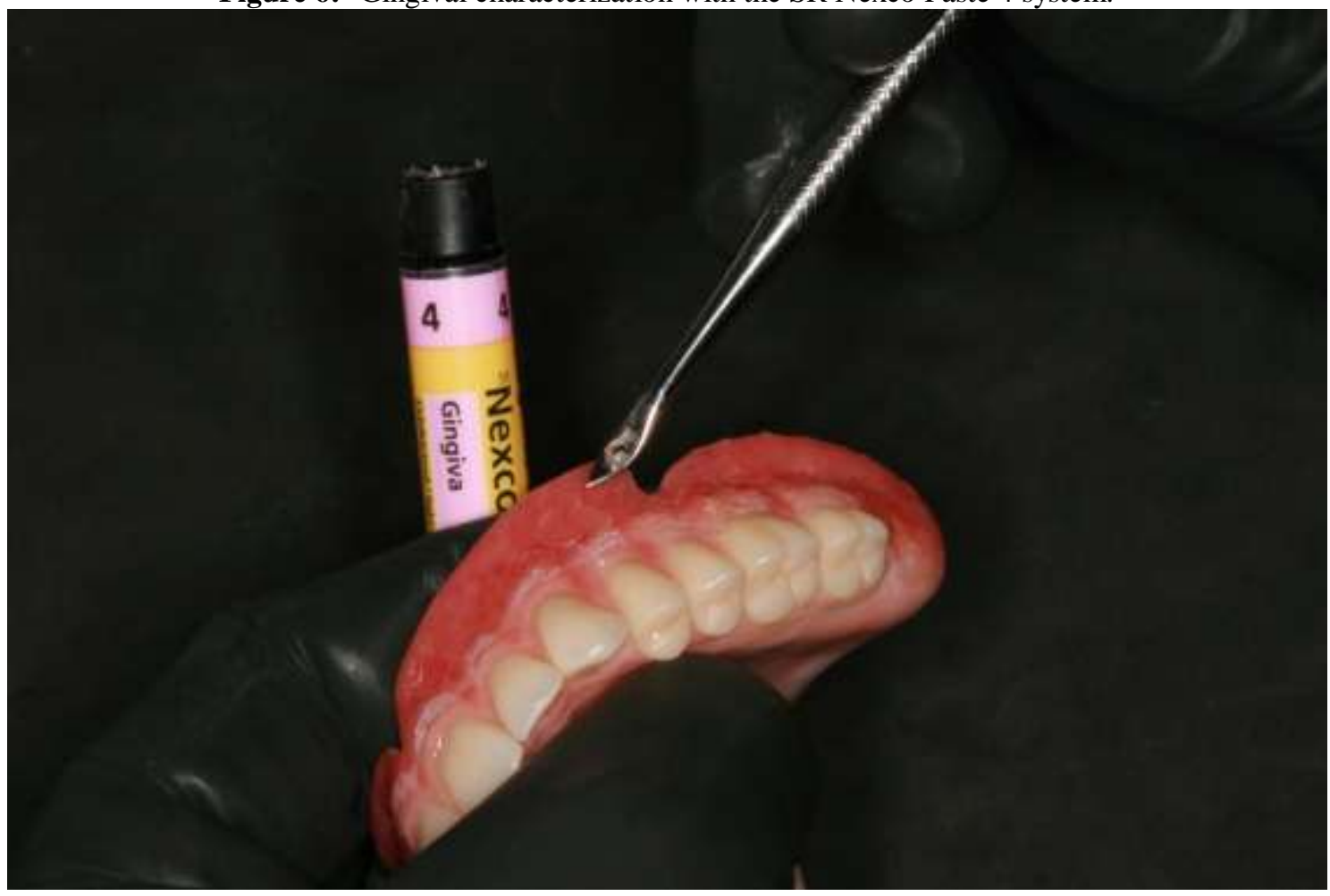

Figure 7:- Total dentures completed after polymerization of the last resin layer.

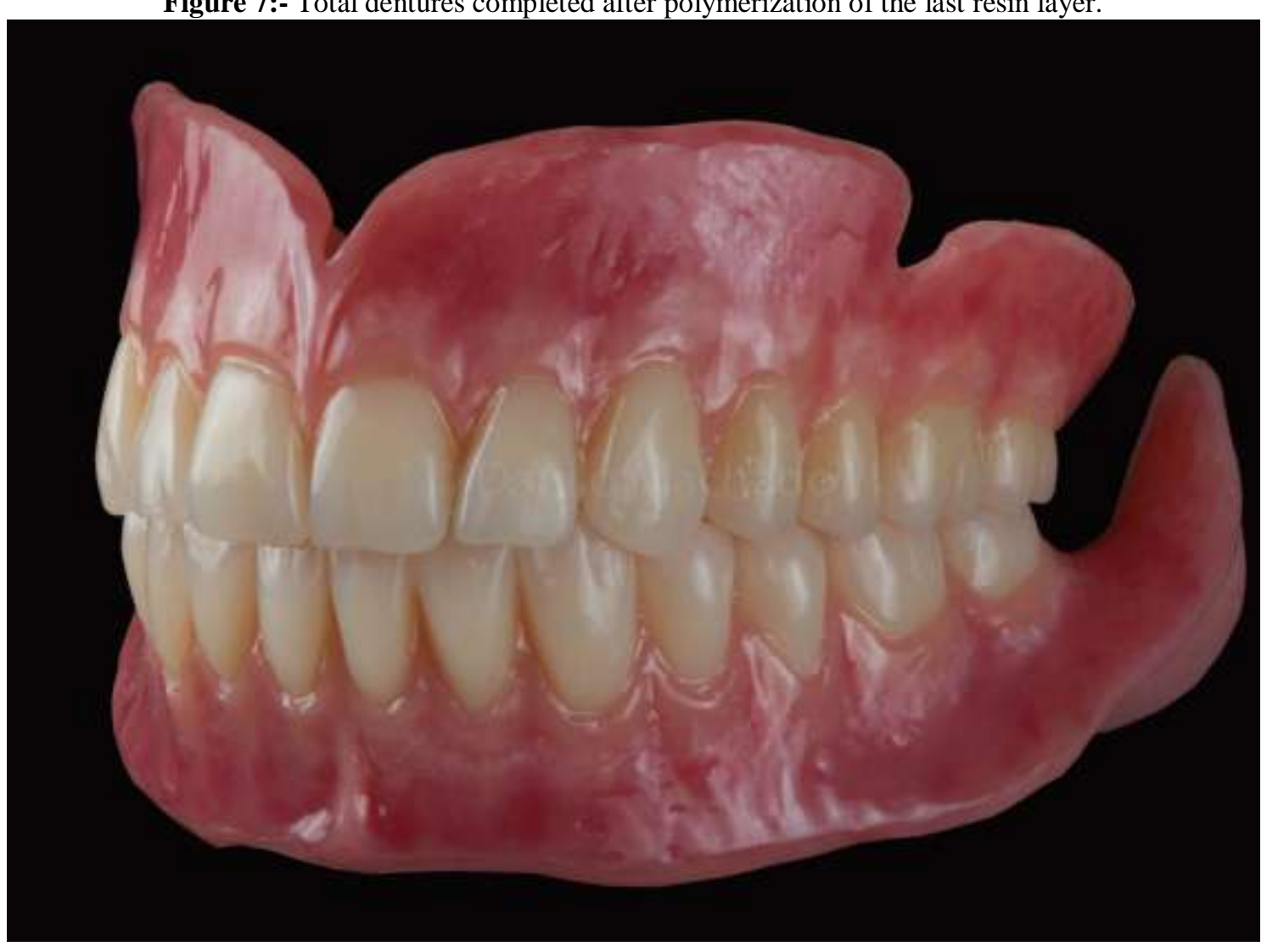


Figure 8:- Proof of the completed dentures.

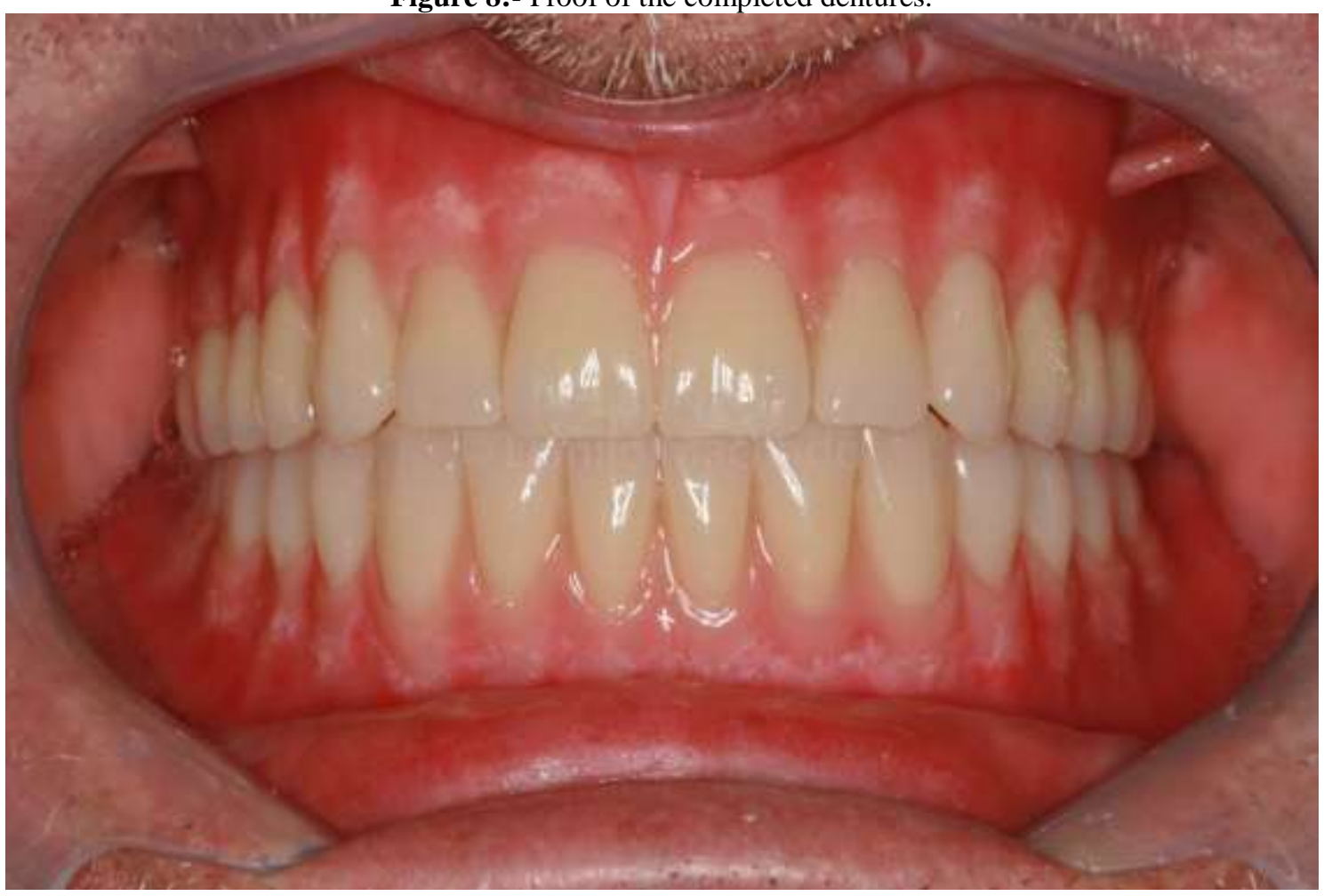

Figure 9:- Aspect of the finished case.

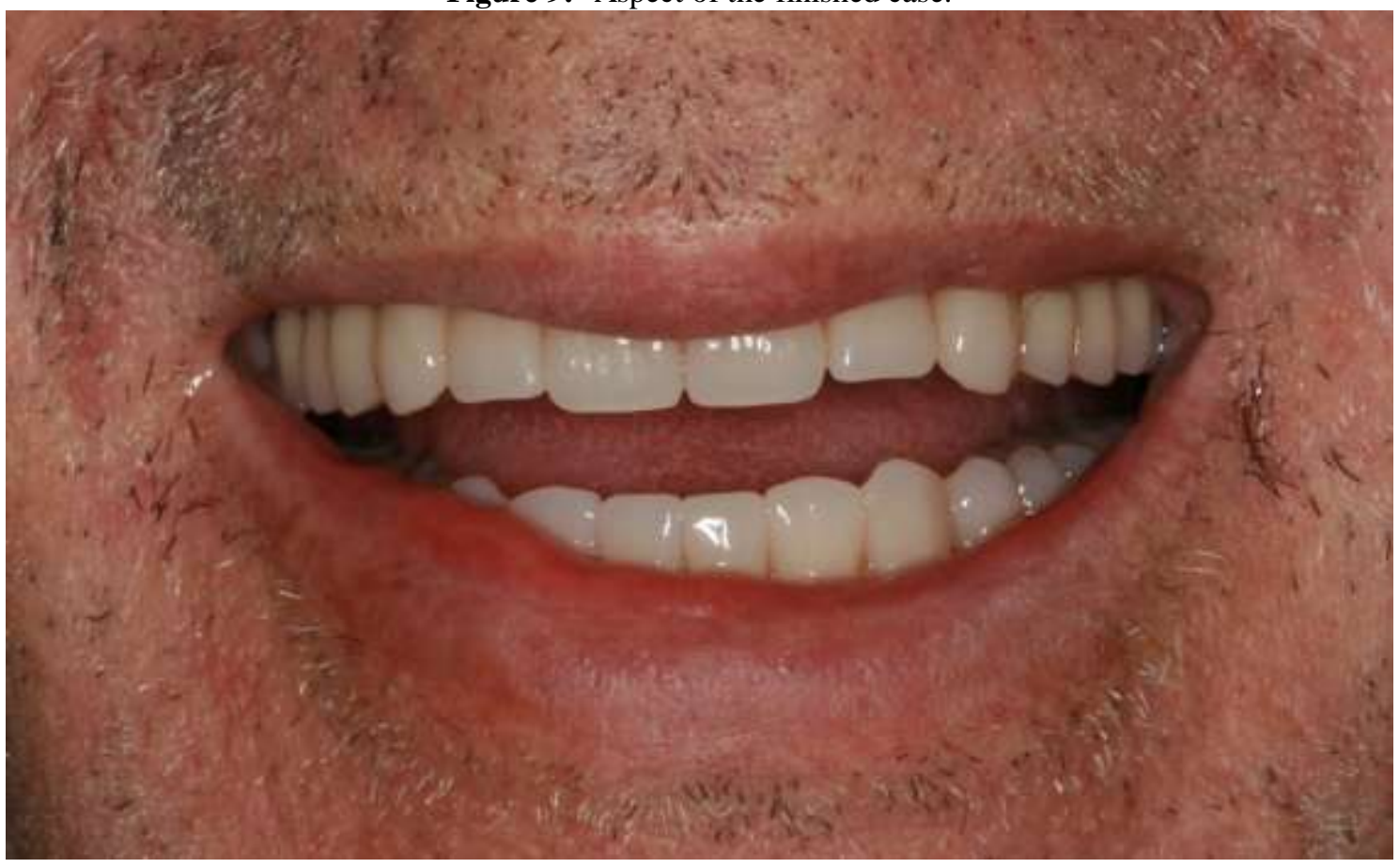

\section{Conclusion:-}

With the use of this new system of gingival characterization associated with the skills of the dental surgeon and dental technician, a very satisfactory result was obtained. 


\section{Conflict of interests}

There is no conflict of interest between authors.

\section{References:-}

1. Heintze SD, Zimmerli B. Relevance of in-vitro tests of adhesive and composite dental materials. A review in 3 parts. Part 2: non-standardized tests of composite materials. Schweiz Monatsschr Zahnmed. 2011;121(10):91630.

2. Wassell RW, McCabe JF, Walls AW. Wear characteristics in a two-body wear test. Dent Mater. 1994;10(4):269-74.

3. Heintze SD, Forjanic M, Ohmiti K, Rousson V. Surface deterioration of dental materials after simulated toothbrushing in relation to brushing time and load. Dent Mater. 2010;26(4):306-19.

4. Lee YK, Lu H, Powers JM. Measurement of opalescence of resin composites. Dent Mater. 2005;21(11):106874.

5. Geurtsen W. Biocompatibility of resin-modified filling materials. Crit Rev Oral Biol Med. 2000;11(3):333-55.

6. Schmalz G. The biocompatibility of non-amalgam dental filling materials. Eur J Oral Sci. 1998;106(2 Pt 2):696706.

7. Elzarug YA, Galburt RB, Ali A, Finkelman M, Dam HG. An in vitro comparison of the shear bond strengths of two different gingiva-colored materials bonded to commercially pure titanium and acrylic artificial teeth. $\mathrm{J}$ Prosthodont. 2014;23(4):313-9

8. SR Nexco Paste Scientific Documentation, Jun 2012.

9. SR Nexco Paste. Instruções de uso, 2012-08/REV.1

10. Oliveira, J. A. D., Ribeiro, É. D. P., Conti, P. C. R., Valle, A. L. D., \& Pegoraro, L. F. (2002). Condicionamento gengival: estética em tecidos moles. Rev. Fac. Odontol. Bauru, 10(2), 99-104

11. Quesada, G. A. T., Rizzardi, M., Franciscatto, L. J., \& Arrais, F. R. (2014). Condicionamento gengival visando o perfil de emergência em prótese sobre implante. Saúde (Santa Maria), 9-18. 